\title{
"The Blue Table Means you Don't Have a Clue": The Persistence of Fixed-Ability Thinking and Practices in Primary Mathematics in English Schools
}

\author{
Rachel Marks ${ }^{1}$ \\ Department of Education \& Professional Studies, King's College London
}

\begin{abstract}
The use of structured ability grouping is increasing in English primary schools and is regularly seen in primary mathematics classrooms. Ability is a normalised discourse with beliefs that some individuals are 'born to do maths' permeating society and infiltrating school practices. In this paper observation and interview data illustrate the persistence of fixed-ability thinking, even in situations where explicit ability-grouping practices are not used. The data analysis suggests a mismatch between mixed-ability practices and fixed-ability thinking, and the paper argues that change will be difficult.
\end{abstract}

\section{A NOTE ON TERMINOLOGY}

Throughout this paper ability (and its derivatives, e.g. mixed-ability) is presented absent of quotation marks to aid the readability of the paper. However, the reader should assume that the legitimacy of the concept - and its associated assumptions - is continually in question and challenged throughout the paper.

\section{INTRODUCTION}

This paper examines the persistence of fixed-ability thinking through the stories and experiences of pupils and teachers in two Year 4 (ages 8-9) mixed-ability mathematics classes in a school where the staff have a reputation for their commitment to the use of mixed-ability teaching and the integration of pupils with Special Educational Needs. It presents a cautionary tale; due to the strong ability ideology in English society - and hence in education - change in overt practices may not always be accompanied by change in fundamental thinking, resulting in the continuation of some fixed-ability thinking and practices. This is not a story about teachers doing something 'wrong', but about a widespread lack of awareness of the strength of the orthodoxy of fixed-ability. It shows how this orthodoxy continues to permeate practice, even when practitioners believe they are acting in accordance with mixed-ability principles. In essence, this paper highlights the continuing mismatch, described ten years ago by Dixon et al (2002), between mixed-ability practices and fixed-ability thinking.

\footnotetext{
${ }^{1}$ Dr Rachel Marks (rachel.marks@kcl.ac.uk) taught in primary schools for 5 years before completing her ESRC funded doctorate entitled "Discourses of Ability and Primary School Mathematics: Production, Reproduction and Transformation". Her research interests include primary mathematics, ability-grouping and equity issues.
} 
Our growing scientific awareness suggests that mathematical-ability has only moderate heritability. Research highlights the crucial and dynamic role of environmental differences in performance outcomes (Shenk, 2010). Despite this, Plomin et al. (2007) found that more than $90 \%$ of teachers and parents believe genetic influences to be more than or at least as important as environmental factors. Such beliefs have their origins in a long history of psychometrics in the UK (e.g. Galton, 1869/1978). The legacy of this continues to dominate popular culture, naturalising a discourse of ability, and legitimising these beliefs in educational practice. Swann, Peacock, Hart \& Drummond (2012, p. 2) demonstrate how this legacy plays out in educational policy with "deterministic, even fatalistic" assumptions about children's capacity in policy documentation. As I write this, Michael Gove (the current Education Secretary) has recently announced plans for a new framework for Key Stage 4 (ages 14-16) assessment and the English Baccalaureate; this consultation paper and the ensuing media frenzy are saturated with unquestioned deterministic assumptions and discussion of identifying and addressing ability differences.

The use of ability in the media (and society more generally) and the lack of hesitation people have in ranking individuals in terms of intelligence (Howe, 1997) provides evidence of White's (2006) argument that Galtonian accounts of general intelligence have so influenced common understanding that we no longer have the capacity to see them as peculiar. This lack of questioning carries over into educational practices. Teachers are expected to “behave as if children's potential is predictable and their futures knowable far in advance" (Swann, et al., 2012, p. 1). Fixed-ability thinking is a major driving force in educational practice and, particularly in the case of mathematics, a driver in a can / can't do dichotomy readily used by society to label oneself and others, often without shame. Such deeply ingrained beliefs mean that change is hard.

\section{THE RESEARCH STUDY}

This paper draws on data from a larger project exploring discourses of ability in primary mathematics (Marks, 2012b). The aim of the study was to examine how ability is conceived and its impacts on teaching and learning mathematics across two schools - Avenue Primary and Parkview Primary ${ }^{2}$ - using contrasting environments to explore how ability-based structuring practices play out in different environments. The focus within each school was on the top and bottom sets, or mixed-ability classes, of pupils in Year 4 (ages 8-9) and Year 6 (ages 10-11). Three teacher-selected focal pupils, representing the range of attainment ${ }^{3}$ in each class/set, were followed for the duration of the academic year. The study involved 284 pupils, 24 of whom were focal pupils, and eight focal teachers.

Data for this paper come from the two Year 4 mixed-ability classes at Parkview Primary. This paper focuses on data from interviews with the focal pupils and field notes written during observations of these classes. The qualitative data were collated in NVivo and analysed using constructivist grounded theory (Charmaz, 2006). Excerpts from the interviews and field notes were extracted to illustrate the themes which emerged through the analysis and are discussed in this paper. These

\footnotetext{
${ }^{2}$ All names in this paper are pseudonyms

${ }^{3}$ Teachers were asked to select an attainment range. Every teacher in the study, having selected their focal pupils, referred to them as high, middle, and low ability.
} 
data extracts typify the data coded within each theme and in many cases a range of similar data extracts were available. The data presented here were selected to best illustrate the theme discussed.

The study highlighted the pervasiveness of discourses of ability in primary mathematics and the ease with which pupils and teachers used such language with an acceptance of its accompanying limitations. Ability-based practices - and their effects - strongly mirrored the literature on ability in secondary mathematics (Marks, 2012a) with specific practices, such as a process of educational triage, identified within the primary environment. Further, unintended consequences were also explored, revealing the deeply limiting impacts of ability-driven educational structures on all pupils.

\section{PARKVIEW PRIMARY AND THE YEAR 4 CLASSES}

Parkview Primary is located on the outskirts of a local town centre serving a diverse area of owneroccupied and council-owned properties. It is a 3-11 mixed mainstream primary school with Designated Special Provision for pupils with Special Educational Needs. Parkview is almost twice the average primary school size with nearly 450 pupils on roll. Approximately a third of the pupils are eligible for Free School Meals. Contextual Value Added scores indicate that Parkview pupils make progress across Key Stage 2 (ages 7-11) in line with expectations, although their aggregated results for mathematics are slightly lower than in other subjects. The school is housed within an old building and bounded by a railway, housing and roads on all sides. The old building lends itself to a feeling of austerity yet this is punctured by the sounds of pupils and through the display of bright artwork. Although pupils are encouraged to walk around the school quietly, this is not always observed; combined with the tight enclosed stairways and echoing corridors, the school rarely seems quiet.

Parkview was recommended to me as a school which had a reputation for using mixed-ability teaching. Pupils from the Designated Special Provision Unit were regularly integrated into mainstream classes and the school employed a high number of support staff within the mainstream school to support such integration and mixed-ability teaching. The head-teacher, Miss Attwood, was prominent in leading this and she expected that the teachers would adhere to her philosophy. Prior to my research I spoke with her to assess the suitability of Parkview for the study. This meeting began well; Miss Attwood talked at length about her beliefs about mixed-ability models, she explained how mixed-ability teaching was applied throughout the school and her disappointment at the perceived need for setting in Year 6 due to external assessment pressures. In order to assess the extent to which teaching was free from fixed-ability thinking I asked about grouping in classes and was assured that ability-grouping was not used. Before I could probe further, we were interrupted by crying carrying down the corridor. This was followed by the appearance of Adina, a small 7-yearold girl at Miss Attwood's door. Miss Attwood brought Adina into the room with us, explained who I was and involved her in our discussion. I returned to the previous question of classroom organisation, particularly in mathematics lessons; Miss Attwood talked about pupils being sat in mixed table groups, then turned to Adina and asked her if that was correct:

No Miss, Miss Mason makes us go and sit in our maths groups, there's the green table, the purple table, the blue table, the yellow table and the red table. The green table are the best at doing maths; I'm on the red table. 
Miss Attwood was clearly taken aback by this, explaining to me that she was not aware such abilitygrouping was used. This lack of awareness highlights how pervasive ability practices are and how they are so normalised in the English education system that they occur unnoticed even by insiders.

The two Year 4 classes at Parkview, on the surface, were arranged very differently for mathematics with respect to ability-practices. Mrs Ellery imposed a system of within-class ability-grouping for most mathematics and literacy lessons, with tables labelled by colour. Although Mrs Ellery referred to the groups (when talking to me) as ability-groups, they were predominantly formed on the basis of pupils' Key Stage One (ages 5-7) test results suggesting that Mrs Ellery conflated, to some extent, attainment and ability. Pupils did not move groups except in the case of severe behavioural issues where they were withdrawn to a separate non-labelled table. In contrast, Mr Donaldson, the teacher of the other Year 4 class at Parkview, introduced groups he referred to as mixed-ability. These groups were constructed around current attainment levels, allowing higher attaining pupils to assist weaker pupils. Pupils moved places fairly regularly dependent on the content of the lessons and pupils' assumed strengths and weaknesses.

\section{MIXED-ABILITY TEACHING: FREE FROM NOTIONS OF FIXED-ABILITY?}

Year 4 pupils at Parkview were not subject to rigid between-class structured ability-grouping, a practice which appears to be on the increase in English primary schools (Hallam \& Parsons, 2012), yet they still experienced the effects of fixed-ability thinking. This section of the paper describes some incidents in Mrs Ellery's and Mr Donaldson's mathematics classes, using them in a critical examination of the notion of mixed-ability practice, asking whether this is really free from fixedability thinking.

\section{Classroom Grouping and Labelling}

Within-class grouping - usually based on some notion of ability - is a common response to organisational decisions in primary classrooms and often believed by teachers to be free of the iniquitous impacts of between-class ability grouping practices such as setting and streaming. However, this study has suggested that, particularly where there is limited between group movement, within-class grouping carries many of the same issues as between-class grouping. Whether these table groups are demarcated by number, colour or an assortment of animal and object names, group-labels carry meaning, allowing something very complex to be conceived very simplistically. Pupils in Mrs Ellery's class demonstrated an understanding of the meanings and experiences attached to the different colour groups, an understanding that was similar amongst pupils:

Jessica: Green means that you're clever and that you know a lot of maths and you get the hardest maths. There's blue, yellow, purple, orange and green but orange and green are kind of the same. I'm green that's top. Orange is kind of the same as green but they're not as confident as green, purple and yellow are the middle and blue gets the easiest work and Mrs Ellery normally works with them ... There, on the green-table, that's the toptable. The one there is the bottom and then it goes there, there, there, 
there, blue, yellow, purple, orange and green. Blue is bottom for children who aren't so confident at maths and they need easier work than the other people, like she doesn't give them so high numbers, she does lower numbers, like we get thousands sometimes and they just get tens or something.

Kelly: $\quad$ Mrs Ellery puts us into different groups, like maths groups, and she moved me from here to here. This means that you're good at maths, this means you are half at maths, the blue table means you don't have a clue.

Across the study, pupils took on, and saw themselves in terms of, group identifiers. It was not uncommon for pupils to refer to themselves as a 'green person' or a 'hedgehog', and in so doing identify, not necessarily explicitly, with the limited ability and mathematical identities available to that group, limiting how they could act and who they could be. Even in the absence of group labels, ability identifiers so saturate the English education system that pupils are provided with ample labels to form the same categories and judgements of themselves and others. The experiences described in Reay \& Wiliam's (1999) study conducted in the mid-1990s in which pupils saw themselves in terms of their ascribed National Curriculum Level are likely to be even more salient in today's classrooms where pupils are expected to know the sublevel at which they are working and where they recognise the "enormous authority" these carry (Yarker, 2002, p. 53). Indeed, in the present study, pupils regularly referred to groups as 'the $3 \mathrm{As}^{\prime}$ ' or the ' $2 \mathrm{Cs}$ ', removing all sense of individuality and building fixed mathematical identities around these labels.

\section{Teacher Expectations}

Whilst group names and ability labels are obvious conveyers of notions of fixed-ability, the central argument of this paper is that fixed-ability thinking continues to manifest itself even in classroom situations not dominated by explicit grouping and labelling. Teachers and pupils still act as if individuals come hard-wired with a fixed-ability, adjusting - and often limiting - experiences and expectations accordingly. The well documented Pygmalion effect (Rosenthal \& Jacobson, 1992) is difficult to eradicate; subtle and not-so-subtle ability identifiers saturate education and impact on the way teachers and pupils behave towards one another. This persistence of fixed-ability thinking is illustrated in the following classroom examples.

In this first example, Mrs Ellery's class are working on a mathematics problem-solving lesson on multiplication. The pupils are working in pairs, and although they are all doing the same task, these pairs are generally ability-based as pupils are sat on their mathematics tables. The lesson observation extract below describes the task and the pupils' and teacher's responses.

Pupils have to choose 12 animals in any number of groups (e.g. 4 cats, 5 spiders, 2 ducks and 1 elephant) and work out how many wellington boots the animals would need in total. The teacher goes through the task on the Interactive White Board showing the pupils how to work it out and how to complete the given table before doing it themselves with their choice of animals.

A pair of pupils on the blue (labelled by the teacher as the lowest ability) table talk animatedly about the animals they are choosing, laughing that they are going to pick underwater animals without any legs so their answer will be zero. They choose 5 goldfish, 
5 whales and 2 sharks. They write out the maths as they have been asked, to show that their animals require no wellingtons and get up excitedly to show what they have done to the teacher. The teacher looks very briefly at their work, tells them the table is untidy and their handwriting difficult to read before telling them off loudly in front of the class for not picking sensible animals and not doing the task properly. They are given a clean sheet and told to repeat the task correctly. The pupils return to their table but do no further mathematical work, instead talking and fiddling with classroom equipment.

Towards the end of the lesson, the teacher asks some pupils to share their work with the class. A pair from the green (labelled by the teacher as the highest ability) table goes to the front and shows their work to the class. Before looking at the maths they have done, the teacher praises them for completing the work so neatly saying that this makes the maths they have done easy to understand. The teacher then asks one of the pair to read out what they have written to the class whilst the other pupil completes the table on the Interactive White Board. The pupils write:

\begin{tabular}{|l|c|c|c|}
\hline Animal & Number & Legs & Boots \\
\hline Worms & 4 & 0 & 0 \\
\hline Sharks & 6 & 0 & 0 \\
\hline Snakes & 2 & 0 & 0 \\
\hline \multicolumn{2}{r|}{} \\
\hline
\end{tabular}

The teacher laughs along with the pair and the rest of the class, telling them they are very clever choosing animals with no legs. She praises the pupils for their good thinking.

This account illustrates how teachers may respond differently to similar situations. This is an illuminating extract because these situations occur within the same lesson, with the same teacher, and within approximately 20 minutes of each other. It could reasonably be expected that when the teacher encountered the second situation she would still have some memory of the first. The first pair of pupils encountered a negative reference to non-mathematical aspects of their work and two behavioural reprimands audible to the class. The second pair of pupils encountered positive teacher engagement, reference to their neat work with some, albeit minimal, linkage made between this and a mathematical context, and praise encompassing words including 'clever' and 'good' which the rest of the class were encouraged to be a part of through sharing in the teacher instigated laughter.

It is not possible to say that the differences in the reaction of the teacher are entirely due to fixedability thinking and resultant assumptions about the work and behaviour of different pupils, yet this is potentially a relevant factor. Whatever the rational for the different treatment, pupils pick up on these differences and incorporate them into their productions (developed understandings of the foundations and implications) of ability. Hence, even if the teacher's actions are unrelated to fixedability thinking, the actions may have ability related effects.

The first pair of pupils - expected to perform a low-ability identity - break out of these expectations, performing aspects of a high-ability identity: working quickly, getting their work correct (the mathematics they completed was correct for the numbers chosen) and working with enthusiasm. 
These behaviours are reconstructed by the teacher, realigning the pupils with their low-ability identity. Rather than acknowledge that they have worked quickly, their work is referred to as difficult to read. This comment, highlighting common value-judgements about neatness in primary classrooms, ties in with, and strengthens, pupils' productions of ability. Through disapproving of the pupils' approach to the task, the teacher draws the attention of other pupils to what have been reworked as poor classroom behaviours.

The second pair of pupils produced limited work in comparison to other pupils given the numbers chosen and the limited mathematics involved. They produced the same quantity of work in the lesson that the blue-table pair had completed 20 minutes earlier. However, the teacher makes no reference to this, instead focussing on positive aspects of the work, linking these to being mathematical and potentially strengthening a mathematical as opposed to behavioural identity for these pupils. It is possible that the teacher's production of them as able, feeds into her production of them as working mathematically. Whilst the teacher did not identify the first pair's work on multiplication by zero as mathematical, having time to think this through, and then having it represented to her by a perceived able pair, may have allowed her to reconstruct multiplication by zero as important and mathematical, rather than time-wasting and inappropriate.

\section{Pupil and Teacher Co-construction}

The extract above illustrates how fixed-ability thinking may persist on a whole-class level. Evidence from this study also suggests similar persistence at a more individual level. At Parkview, Mrs Ellery and $\mathrm{Mr}$ Donaldson collaborated on their lesson planning, meaning that the same lesson content was often delivered to both classes. Mr Donaldson also conducted the Wellington boot lesson, although pupils in his class worked individually. Whilst pupils were sat on mixed-ability tables, there appeared to be differences in the quality of the teacher-pupil interactions that took place. Whilst much of the interaction comprised of normal classroom discourse - explanations, behavioural reprimands, etc. Mr Donaldson's interactions with one pupil, George, whom Mr Donaldson had selected as a highattaining focal pupil, appeared qualitatively different.

Mr Donaldson: How are you getting on?

George: I've made the work interesting. I've got a 306-legged millipede

Rather than being reprimanded as may have been the case with other pupils, Mr Donaldson positively encouraged this despite George spending an inordinate amount of the lesson time drawing the 306 legs on his millipede. Later within the lesson, Mr Donaldson returned to George and a degree of banter developed in their interaction:

George: I've finished; what should I do now?

Mr Donaldson: Perhaps you could work out how much the boots will cost. Shall we say they're 99p each?

George: $\quad$ Are the different sizes different prices?

Mr Donaldson: They could be. Or they could be on sale. 
George:

Or special offer.

This interaction had two possible impacts: it highlighted behaviours believed to be indicative of highability and it gave a high-attaining pupil access to mathematical thinking. The banter set up between George and Mr Donaldson could be thought of in terms of co-construction in which they are working together and off of each other's responses, drawing on notions of fixed-ability, to strengthen George's identity within the class as mathematically able/high-attaining - with these terms used interchangeably by Mr Donaldson (and other teachers) - and to cement notions of fixed-ability more generally for the whole class. Such co-constructive work was a regular feature of all classes in this study (for further discussion across schools see Hodgen \& Marks, 2009), focussing on a range of features from attainment to behaviour, as this interaction between George and Mr Donaldson in a separate lesson illustrates:

The class are working on fractions, identifying fractions of shapes and naming different fractions put up on the Interactive White Board. Pupils are only required to count the number of shaded blocks and the total number of blocks in giving their answer, for instance 3/6, rather than consider equivalent fractions. The shape on the board shows 2 out of 4 blocks shaded. Mr Donaldson writes this up as 2/4 and then asks George how we should say 2 over 4 . Initially, and quite audibly - I am sitting on the other side of the classroom and the answer is clear - George replies two fourths. Apparently looking for the answer of two quarters and so hearing this answer as incorrect, Mr Donaldson says he can't hear the answer because other pupils, pointing out two he had previously (when talking to me) referred to as low-attaining, are talking and he will have to wait for quiet, drawing attention to this behaviour rather than to the incorrect answer. He then returns to George, saying "I think what you said was two quar..." funnelling the response which George picks up on, giving the expected answer of two quarters.

In this extract George and the teacher work together reproducing two distinct identities: a highability identity with an academic focus - in this case on correctness - and a low-ability identity with a predominantly behavioural focus, in this case on talking and anti-school behaviours. This interaction is suggestive of Holland et al.'s (1998) improvisation as the teacher supports George's identity work through unplanned "extensive teacher prompting" (Doyle \& Carter, 1984, p. 132) and funnelling (Bauersfeld, 1988) to ensure correctness whilst additionally drawing other pupils' attention to the misbehaviour of another pupil. Importantly, the interactions in the above extracts rely on the teacher holding fixed-ability beliefs and as such seeing the pupils as capable of reaching different points academically and of being likely to engage in particular behaviours. Although Mr Donaldson did not sit pupils in explicit ability groups or apply explicit ability labels, his differential expectations and the subtle differences in the learning experiences afforded to different pupils still constitute fixed-ability thinking, suggesting just how persistent such thinking is.

\section{Pupils' Fixed-Ability Thinking}

The extracts discussed bring out the possibility of persistent fixed-ability thinking in teachers' practices. The study also revealed the strength of very young pupils' productions of ability, drawing heavily on social understanding of heritability in individuals' levels of mathematical ability and the possibility - or not - of extending their current level of mathematical attainment. As such, there is also persistence in pupils' fixed-ability thinking and this revealed itself both when pupils' talked 
about their current and future attainment but also in how they interacted with other pupils in the mathematics classroom. Returning to George, the following extract illustrates how fixed-ability thinking, intensified by classroom practices, may have influenced his interactions. During the lesson, in which pupils were working on telling the time using analogue clocks, George was working with Oliver, a low-attaining pupil, playing a game in which they had to show clock times for each other to identify:

\footnotetext{
Each pupil has a small geared analogue clock. They take it in turns to make a time for their partner to identify and award a point if they get the time correct. Initially, George appears to be helpful to Oliver, selecting simple times - on the hour or half past - and helping Oliver attain the correct answer and obtain a point. George maintains this for a while, with the boys' scores being equal. Then, Mr Donaldson tells them that they have two minutes left. George whispers to me "I'll do him a really hard one, even though he's not going to get it." On his next two turns, George chooses 5 past 12, telling me "he'll think it's 1 o'clock" and then 7 minutes to 6 which may have been selected to look like half past 10. On the basis of these, George moves two points into the lead as Mr Donaldson asks them to stop. Mr Donaldson asks them to put their hands up if they won, and George raises his hand high.
}

Here, George appears to apply fixed-ability judgements to manipulate the outcome of the task to his advantage. He appeared to be aware, as was common practice for Mr Donaldson, that they would be asked who had obtained the most points and that this could be used to strengthen his position in the class and maintain his identity as mathematically-able. A simple practice of awarding points moves the focus away from the mathematics and makes this a competitive exercise. It relies on an assumption of difference between pupils and that some will obtain more points than others. It is possible that this draws on beliefs of fixed-ability. This alters pupils' access to the mathematics George gave Oliver either examples that he could already complete or examples that were too far advanced to extend his current level of working - and to supportive collaborative relationships, as pupils are forced into a position of competing against each other. Initially, George appeared to be supportive of Oliver, but this changed when his ability-identity was potentially at stake. Fixed-ability thinking influences George's interactions; he has been set up as mathematically able and all classroom practices (and potentially messages he receives outside of school) work towards intensifying this position. He is then seen to reproduce interactions with their basis in fixed-ability thinking.

\section{DISCUSSION: OPPORTUNITIES FOR CHANGE}

This paper has presented a number of extracts of pupils' mathematical learning experiences in mixed-ability classes. It would reasonably be expected - and the head-teacher at Parkview Primary had the aim of achieving this - that such classes would be characterised by parity, where all children had the same access to a range of learning experiences and where children were not thought about or characterised in terms of fixed-ability thinking and innate learning limits. However, these lesson extracts, which are by no means unique, illustrate how fixed-ability thinking continues to pervade teaching and learning practices and pupil-teacher interactions even in mixed-ability environments. An ability discourse, even when used in apparently "benign" (Dixon, et al., 2002, p. 9) ways, and an 
ideologically driven tendency to think about individuals in terms of capacity and limits, continues to present itself, even outside of explicit grouping, in classroom practices.

The continuation of fixed-ability driven practices has important consequences for pupils' mathematical engagement and learning, both now and in the future. Although possibly more subtle, these children are receiving the same messages about their ability, a notion conceptualised in terms of innate limits, as they may have done in more overtly ability organised and driven classes. It is perhaps interesting to note that across the wider study, all the focal pupils, including those in the Year 4 classes at Parkview discussed here, readily defined ability and identified their own class position, the position of their peers, and the innate and immoveable limits to their mathematical learning that they and their peers had. All pupils were receiving and assimilating messages about human capabilities based on assumptions of fixed-ability as a result of classroom interactions direct or witnessed - interactions based on fixed-ability thinking which occurred independently of classroom organisational structures. It is important to note that many of the negative and iniquitous impacts of setting and streaming discussed in the literature derive from the differential learning experiences afforded to different pupils rather than from setting per se. The extracts in this paper suggest that these differential learning experiences persist, as the ideology on which they are built is so strong, in the mixed-ability mathematics classroom. Boaler (2005) identified how setting structures create "psychological prisons", limiting individuals' engagement with mathematics well beyond school. It may be the case that a mixed-ability mathematics class, still driven by assumptions of fixed-ability, has less obvious prison walls, but the conditions and lasting impacts may be very similar.

Whilst this may seem a rather pessimistic paper in highlighting how saturated everyday classroom practices are with notions of fixed-ability, it can equally be thought of as providing space to engage with these practices and notice just how persistent notions of fixed-ability are. It is drawing attention to assumptions underlying practices that we begin to understand where and how change needs to be directed. Importantly, this paper highlights that it is partly what is done - by teachers and others - within a structural organisation, as opposed to just the structural organisation, that matters. Change needs to go far deeper than a surface change to structural practices. The extracts in this paper illustrate how seemingly innocuous interactions may be driven by notions of fixed-ability and the extent to which stratified practices may appear so natural as to go undetected, even by the enactors, within the classroom.

If fixed-ability thinking is so persistent, how do we bring about change? Change clearly is possible as evidenced by the experiences of the teachers and pupils across the Learning Without Limits projects (Hart, Dixon, Drummond, \& Mclntyre, 2004) and some of the experiences reported in this special issue. However, the evidence presented in the extracts in this paper suggest that simply changing from a structured grouping to a mixed-ability model is unlikely to be enough; the underlying thinking needs to be addressed and considered holistically to bring about sustained change. Teachers need to be given opportunities to critically engage with their practices, to reflect on 'normal' interactions and have the space to identify the forces driving their actions. The teachers interviewed in this study found it difficult to justify some of the practices they engaged in but admitted, in the highly doctrinaire, prescriptive and accountable educational culture we currently have, they have never had the time to engage with the practices they enact or to think about why they act, or have been instructed to act, in particular ways. Unfortunately the collaborative thoughtful approaches to 
teaching practices documented in projects where change has been successful are scarce in most schools, not through the wrong-doings of the schools or teachers, but through a legacy of fixedability thinking which permeates not only schools, but society more broadly. It is natural to assume that these messages and accompanying stratified practices must be correct and hence justified when one unchallenged view of human capacity dominates so much of our lives. Change will be difficult but we have evidence to present a more positive picture. It will involve working at the deeply embedded layers of fixed-ability beliefs underscoring education in England. However the rewards of achieving such change surely outweigh the efforts of getting there; in the absence of fixed-ability thinking it should be possible to provide all pupils with access to an engaging and rewarding mathematics curriculum rather than, as we currently have, one which only allows selected pupils to succeed.

\section{ACKNOWLEDGEMENT}

I would like to thank the anonymous schools, pupils and teachers for their commitment to this study. This research was funded by a studentship from the Economic and Social Research Council (award number: PTA-031-2006-00387).

\section{BIBLIOGRAPHY}

Bauersfeld, H. (1988). Interaction, construction, and knowledge: Alternative perspectives for mathematics education. In D. A. Grouws \& T. Cooney (Eds.), Perspectives on Research on Effective Mathematics Teaching (Vol. 1, pp. 27-46). Reston, Virginia: Lawrence Erlbaum Associates / National Council of Teachers of Mathematics.

Boaler, J. (2005). The 'psychological prisons' from which they never escaped: The role of ability grouping in reproducing social class inequalities. FORUM, 47(2\&3), 135-143.

Charmaz, K. (2006). Constructing Grounded Theory: A Practical Guide Through Qualitative Analysis. London: SAGE.

Dixon, A., Drummond, M. J., Hart, S., \& McIntyre, D. (2002). Developing Teaching Free from Ability Labelling: back where we started? FORUM, 44(1), 7-12.

Doyle, W., \& Carter, K. (1984). Academic tasks in classrooms. Curriculum Inquiry, 14(2), 129-149.

Galton, F. (1869/1978). Hereditary genius. London: Julian Friedmann Publishers.

Hallam, S., \& Parsons, S. (2012). Prevalence of streaming in UK primary schools: evidence from the Millennium Cohort Study. British Educational Research Journal. doi: 10.1080/01411926.2012.659721

Hart, S., Dixon, A., Drummond, M. J., \& McIntyre, D. (2004). Learning without limits. Maidenhead: Open University Press.

Hodgen, J., \& Marks, R. (2009). Mathematical 'ability' and identity: A sociocultural perspective on assessment and selection. In L. Black, H. Mendick \& Y. Solomon (Eds.), Mathematical Relationships in Education: Identities and Participation (pp. 31-42). Abingdon: Routledge.

Holland, D., Skinner, D., Lachicotte Jr, W., \& Cain, C. (1998). Identity and agency in cultural worlds. Cambridge, Massacheusetts: Harvard University Press.

Howe, M. (1997). IQ in question: The truth about intelligence. London: SAGE.

Marks, R. (2012a). Ability-grouping in UK primary mathematics education: Mirroring secondary mathematics. Paper presented at the British Educational Research Association Annual Conference, University of Manchester, 4th - 6th September 2012. 
Marks, R. (2012b). Discourses of ability and primary school mathematics: Production, reproduction and transformation. Unpublished PhD Thesis. King's College London.

Plomin, R., Kovas, Y., \& Haworth, C. (2007). Generalist genes: Genetic links between brain, mind and education. Mind, Brain, and Education, 1(1), 11-19.

Reay, D., \& Wiliam, D. (1999). 'I'll be a nothing': Structure, agency and the construction of identity through assessment. British Educational Research Journal, 25(3), 343-354.

Rosenthal, R., \& Jacobson, L. (1992). Pygmalion in the classroom: Teacher expectation and pupils' intellectual development. Bancyfelin, Carmarthen: Crown House Publishing.

Shenk, D. (2010). The genius in all of us: Why everything you've been told about genetics, talent and intelligence is wrong. London: Icon Books.

Swann, M., Peacock, A., Hart, S., \& Drummond, M. J. (2012). Creating learning without limits. Maidenhead: Open University Press.

White, J. (2006). Intelligence, destiny and education: The ideological roots of intelligence testing. Abingdon: Routledge.

Yarker, P. (2002). The Confirmation of Fixed Ability: can't act; can't sing; can dance a little. FORUM, 44(2), 53-54. 